\title{
Perencanaan Ulang Layout Runway Bandar Udara Syamsudin Noor Banjarmasin yang Didasarkan Pada Hasil Analisis Airports GIS FAA
}

\author{
Adhyaksa Adha Rahman, Ervina Ahyudanari, Istiar \\ Departemen Teknik Sipil, Fakultas Teknik Sipil dan Perencanaan, Institut Teknologi Sepuluh Nopember \\ (ITS) \\ E-mail: ervina@ce.its.ac.id
}

\begin{abstract}
Abstrak-Banjarmasin adalah ibu kota Provinsi Kalimantan Selatan. Sebagai pusat dari provinsi Kalimantan Selatan, semestinya fasilitas transportasi antar kota, pulau maupun negara di kota tersebut mampu menangani permintaan jasa transportasi dengan baik. Kegiatan transportasi bersumber dari kebutuhan mayoritas yang beragama Islam sehingga membutuhkan transportasi kegiatan haji, maupun investasi dan pariwisata. Penentuan arah runway sebelumnya didasarkan pada analisis frekuensi dan kecepatan angin dominan pada daerah tersebut. Hasil analisis angin bandar udara Syamsudin Noor Banjarmasin adalah dominan pada 2 arah derajat azimuth, yaitu 100 - 280 dan 135 - 215. Diketahui bahwa dua arah tersebut tidak mencapai prosentase 95\% cakupan, yang menurut ketentuan FAA pada Appendix 2 AC 150/5300-13A mengharuskan adanya runway pada arah angin dominan hingga prosentase $95 \%$ cakupan angin tercapai. Hal ini menunjukkan kebutuhan runway kedua. Dengan didapatkannya literatur dari FAA tentang penggunaan Airports GIS untuk analisis arah runway, maka Studi ini mencoba untuk merencanakan ulang arah runway. Pertama, dilakukan studi literatur mengenai peraturan yang berlaku dan subyek. Kedua, dilaksanakan pengumpulan data seperti data lingkungan dan pergerakan pesawat. Selanjutnya ditentukan kapasitas pergerakan pesawat runway eksisting. Setelah itu, diramalkan tahun pertumbuhan pergerakan pesawat melebihi kapasitas runway. Langkah berikutnya adalah menentukan arah runway dari analisis windrose menggunakan program javascript ALL_WEATHER Wind Rose Form oleh FAA. Sistem runway didapatkan menyesuaikan arah. Terakhir, Runway dan taxiway baru direncanakan. Hasil menunjukkan runway eksisting 10 - 28 memenuhi persyaratan $95 \%$ cakupan angin. Didapatkan kebutuhan runway baru pada tahun 2043. Runway kedua direncanakan berdimensi 3326 x 45 m dengan pemisahan 1035 m.
\end{abstract}

Kata kunci-Bandara, Runway, Pertambahan Runway, Bandara Syamsudin Noor, Airports GIS.

\section{PENDAHULUAN}

$\mathrm{B}$ ANDAR Udara Syamsudin Noor terletak pada kecamatan Landasan Ulin, Kota Banjarbaru, Provinsi Kalimantan Selatan. Bandara ini dibangun dengan nama Lapangan Terbang Ulin pada tahun 1936. Pada masa kependudukan Jepang dan NICA, lapangan terbang ini sempat beroperasi sebagai bandara militer, yang kemudian diganti namanya sebagai nama salah satu pahlawan nasional setelah berdirinya RIS, bandara ini lalu dialihfungsikan sebagai bandara sipil pada 9 April 1970 [1]. Sekarang, bandara Syamsudin Noor melayani berbagai rute domestik dan satu internasional dengan tiga belas maskapai penerbangan nasional, dengan kapasitas penumpang sebesar 3,013.191 penumpang [1].

Banjarmasin adalah ibu kota Provinsi Kalimantan Selatan. Sebagai pusat dari provinsi Kalimantan Selatan, semestinya fasilitas trasnportasi antar kota, antar pulau maupun antar negara di kota tersebut mampu menangani jumlah permintaan jasa transportasi dengan baik. Di kota Banjarmasin maupun keseluruhan provinsi Kalimantan Selatan, terdapat kegiatan ekonomi dan non-ekonomi yang bergantung pada fasilitas transportasi dengan pelayanan yang baik. Kegiatan tersebut bersumber dari demografi penduduk yang mayoritas beragama Islam sehingga membutuhkan transportasi kegiatan haji, maupun keperluan investasi dan pariwisata. Sekain tu perlu juga diketahui bahwa sejak tahun 2010, abdanra Syamsudin Noor adalah bandara dengan wisatawan haji terbanyak di Indonesia [1], sehingga seyogyanya pemerintah menyediakan fasilitas yang dapat melayani masyarakat.

Penentuan lokasi runway tergantung pada analisis frekuensi dan kecepatan angin yang dominan pada daerah tersebut. Ocherudy [2] telah melakukan analisis windrose pada Bandara Syamsudin Noor Banjarmasin dan menyimpulkan bahwa arah angin dominan berada pada arah derajat azimuth 100 - 280 dan 135 - 215. Tabel 1 mengilustrasikan prosentase frekuensi berbagai kecepatan angin pada bandara dengan arah azimuth yang berbeda dan rekomendasi arah angin untuk runway rencana. Dapat diketahui dari tabel tersebut bahwa pada Bandara Symasudin Noor terdapat arah angin dominan lebih dari satu. Seperti diketahui bahwa pesawat terbang memerlukan angin dari arah berlawanan untuk proses take-off. Hal ini agar pesawat mendapatkan energi angkat yang diperlukan pada kecepatan tertentu. Ketika arah angin berhembus berubah-ubah dari arah angin satu ke lainnya, maka pesawat terbang semestinya selalu bergerak berlawanan dengan arah angin tersebut. Hal ini tentu tidak dapat dilakukan apabila runway berjumlah satu. FAA pun mensyaratkan bahwa single runway harus mencakup lebih dari $95 \%$ angin di daerah bandara, dan dibutuhkan runway lain pada daerah angin dominan hingga cakupan angin mecapai prosentase tersebut [3]. Ini menyebabkan adanya kebutuhan akan runway kedua pada bandara Syamsudin Noor.

Airports GIS (Airports Geographical Information System) FAA adalah satuan alat perangkat lunak yang dikembangkan oleh FAA. Satuan software ini bertujuan untuk memfasilitasi pengumpulan data bandara dan aeronautika untuk sistem ruang udara Negara Amerika serikat generasi selanjutnya. Hingga November 2016 saat studi ini dikerjakan, terdapat berbagai data 
angin dari banyak Bandar udara di dunia. Satuan software ini juga mempunyai perangkat analisis windrose semua musim bernama ALL_WEATHER Wind Rose Form [4]. Perangkat ini mempunyai keluaran hasil analisis windrose dengan hasil numerik dan grafik. Input yang dibutuhkan dari perangkat tersebut adalah file .PRN, yaitu data angin yang didapatkan dari perangkat Windrose Rose Form [5]. Proses analisis windrose menggunakan satuan software ini tidak ada perbedaan dengan analisis menggunakan metode manual. Hanya saja, program ini lebih mudah dalam penggunaaannya sebab berbagai faktor analisis yang bisa diubah sesuai keinginan. Contohnya adalah jika pengguna ingin mengubah crosswind yang dibolehkan pada runway, maka pengguna dapat mengganti kolom isian Crosswind Component. Proses tersebut jauh lebih mudah dari mengganti template pada metode manual. Pada intinya, Airports GIS memudahkan analisis windrose untuk perencanaan runway.

Tabel 1

Prosentase Hembusan Angin dan Rekomendasi Landasan Pacu Kedua Bandara Syamsudin Noor Banjarmasin

(Ocherudy, 2016)

\begin{tabular}{|c|c|c|c|c|c|c|}
\hline \multirow{2}{*}{ Arah } & \multicolumn{5}{|c|}{ Kecepatan Angin (knot) } & \multirow{2}{*}{ Total } \\
\cline { 2 - 6 } & $\mathbf{0 - 1 0}$ & $\mathbf{1 1 - 1 6}$ & $\mathbf{1 7 - 2 1}$ & $\mathbf{2 2 - 2 7}$ & $\mathbf{> 2 8}$ & \\
\hline $0-180$ & $34,7 \%$ & $17,73 \%$ & $6,75 \%$ & $0,49 \%$ & $0,49 \%$ & $60,20 \%$ \\
\hline $45-225$ & $34,7 \%$ & $18,82 \%$ & $11,23 \%$ & $1,23 \%$ & $0 \%$ & $66,01 \%$ \\
\hline $90-270$ & $34,7 \%$ & $21,67 \%$ & $10,64 \%$ & $0 \%$ & $0,25 \%$ & $67,29 \%$ \\
\hline $100-280$ & $34,7 \%$ & $20,70 \%$ & $12,81 \%$ & $1,18 \%$ & $0,25 \%$ & $69,67 \%$ \\
\hline $135-315$ & $34,7 \%$ & $19,80 \%$ & $10,54 \%$ & $5,91 \%$ & $0,25 \%$ & $71,23 \%$ \\
\hline $175-355$ & $34,7 \%$ & $19,15 \%$ & $8,13 \%$ & $0,49 \%$ & $0,49 \%$ & $62,99 \%$ \\
\hline \multicolumn{7}{|c|}{ rekomendasi landas pacu 2 } \\
$=$ & $=$ eksisting \\
& $=$
\end{tabular}

\section{II.METODOLOGI}

Bab Metodologi merupakan bab yang menyajikan langkah penyelesaian dari permasalahan dalam studi ini. Adapun isi dari bab ini adalah Studi Literatur yang berisi teori-teori terkait, Analisa Data, Penentuan Letak dan Arah Runway, Peramalan Pertumbuhan Pergerakan Pesawat, Penentuan Tahun Kebutuhan Runway, Perencanaan Runway, Exit Taxiway dan Taxiway Rencana, Evaluasi Kinerja Runway Rencana Dengan Simulasi Waktu Beroperasi, Kesimpulan Dan Saran.

Studi Literatur dilakukan dengan mengumpulkan berbagai bahan referensi yang berhubungan dengan studi. Bahan referensi tersebut termasuk buku teks, jurnal ilmiah, maupun materi perkuliahan.

Studi yang berkaitan dengan studi sebelumnya, yaitu analisis Ocherudy[2] juga dijadikan dasar analisis. Proses penggunaan software Airports GIS FAA juga menjadi literatur penting untuk analisis arah dan jumlah runway.

Dalam studi ini diperlukan data-data sekunder untuk mendukung keakuratan dari hasil analisis, diantaranya adalah:

1) Tipe pesawat yang menggunakan bandara dan karakteristiknya selama 5 tahun belakangan.

2) Layout dan Master Plan bandara Syamsudin Noor Banjarmasin.

3) Sistem runway dan taxiway.

4) Pergerakan pesawat pada setiap jam, hari, dan bulan selama 5 tahun terakhir.
5) Jadwal penerbangan.

6) Kebijakan terkait runway dan taxiway yang berlaku pada Bandara Syamsudin Noor Banjarmasin.

7) Data analisis windrose pada Bandara Syamsudin Noor Banjarmasin.

Setelah semua data sekunder dikumpulkan, maka data-data tersebut dapat dianalisa agar memenuhi tujuan dari studi ini, sebelum memberikan kesimpulan dari studi dan perencanaan yang telah dilakukan. Hasil akhir dari proses analisis data adalah desain runway rencana dan arahnya.

Didapatkan data analisis windrose sebagai data sekunder yang kemudian menjadi input dari penentuan letak dan arah runway. Menentukan arah runway dapat dilaksanakan dengan melihat bentang arah angin dominan dari analisis windrose, yang pada kasus ini akan dilakukan menggunakan Airports GIS FAA

Setelah diketahui arah dan letak runway, diputuskan sistem runway rencana yang akan dianut. Sistem akan mengikuti kombinasi arah kedua runway.

Setelah dilakukan pencarian data maka dilanjutkan ke perhitungan peramalan pertumbuhan lalu-lintas udara tahun yang akan datang. Peramalan pertumbuhan lalu lintas udara dilakukan untuk mengevaluasi kinerja runway akibat penambahan jumlah pergerakan pesawat total di runway di masa yang akan datang. Dihitung pula kapasitas runway eksisting sebagai variabel pembanding peramalan. Pada akhirnya akan diketahui tahun berapakah runway itu tidak akan mampu menampung pergerakan pesawat.

Perencanaan runway dan taxiway menentukan dimensi melalui peraturan-peraturan yang ada. Untuk perencanaan exit taxiway harus ditentukan jalur terpendek dari runway ke apron. Perencanaan runway menentukan dimensi melalui

Setelah direncanakan penambahan runway, maka pergerakan pesawat yang selama ini terpusat pada runway eksisting saja dapat dipecah. Waktu beroperasi harian direncanakan dan dibuat simulasi operasi sistem runway rencana. Hasil dari evaluasi ini adalah kapasitas runway rencana dan penentuan mampunya runway melayani pergerakan pesawat pada keadaan eksisting.

Tahap-tahap pengerjaan penelitian dapat digambarkan sebagai proses dengan awalan dan akhiran seperti diagram alir pada gambar 3.1.

\section{ANALISIS DATA}

\section{A. Analisis Windrose}

Perencanaan runway tidak luput dari desain arah dan lokasi runway tersebut dalam sebuah bandara. Runway kedua bandara Syamsudin Noor pertama harus ditentukan arah bentangnya, serta hubungan fisiknya dengan runway eksisting. Ditentukan pula sistem runway teraman dan paling efisien dengan kondisi di daerah bandara melalui studi literatur pada berbagai buku teks mengenai subyek terkait. Untuk menentukan arah dan letak runway kedua, diperlukan data-data berupa layout bandara, data angin dan analisis windrose.

Kondisi angin sangat menentukan desain atau perencanaan dari sebuah bandara, Tergantung pada arah angin, kecepatan, dan frekuensi yang berbeda, maka akan berbeda pula hasil 
rancang akhirnya. Elemen yang paling dipengaruhi oleh kondisi angin tersebut adalah landasan pacu (runway), dimana arahnya ditentukan oleh analisis windrose. Dari total kejadian arah angin yang terjadi akan diambil parameter angin dominan, yaitu arah angin yang memiliki prosentase kejadian $95 \%$ atau lebih. Kasus dimana tidak ada arah angin dengan kejadian $95 \%$ dari total hembusan, maka akan dibutuhkan lebih dari satu runway.

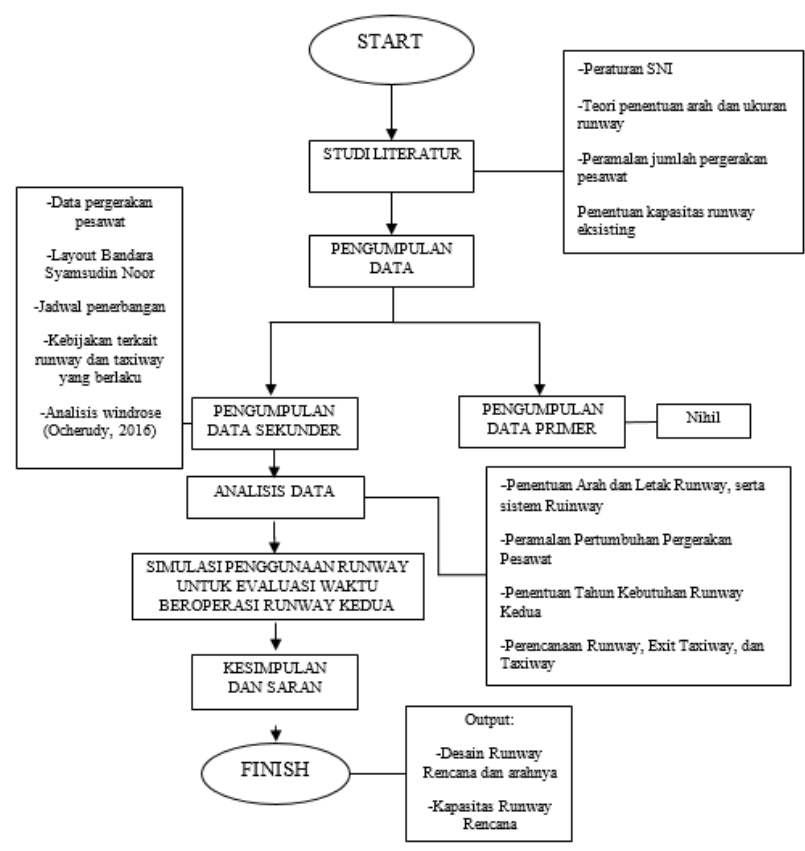

Gambar 1. Diagram alir pengerjaan studi

Hasil analisis membuktikan bahwa cakupan angin arah 100 - 280 sebesar 99,97\%, sudah melebihi standar wind coverage FAA [3]. Hal ini ditambah dengan kecukupan cakupan angin pada arah lainnya membuktikan bahwa runway pada bandara Syamsudin Noor tidak membutuhkan runway tambahan sebagai penambah cakupan angin. Dapat dilihat pada grafik di gambar 4.1 bahwa cakupan angin maksimum berada di runway 0/18 (searah jarum jam) sampai 7/25 dan 11/29 (searah jarum jam) sampai $18 / 36$. Hasil analisis dalam bentuk windrose untuk arah $100-280$ pun bisa dilihat pada gambar 4.2.

\section{B. Peramalan Pergerakan Pesawat}

Perencanaan layout runway memerlukan periode kebutuhan runway ditinjau dari pergerakan pesawat yang diprediksi akan terjadi di masa mendatang. Hal demikian karena runway tambahan direncanakan juga untuk mengakomodasi perkiraan pergerakan pesawat yang melebihi kapasitas runway pertama. Agar runway kedua dapat dimanfaatkan secara maksimal, perlu diketahui kapan waktu runway pertama tidak dapat menampung pergerakan pesawat.

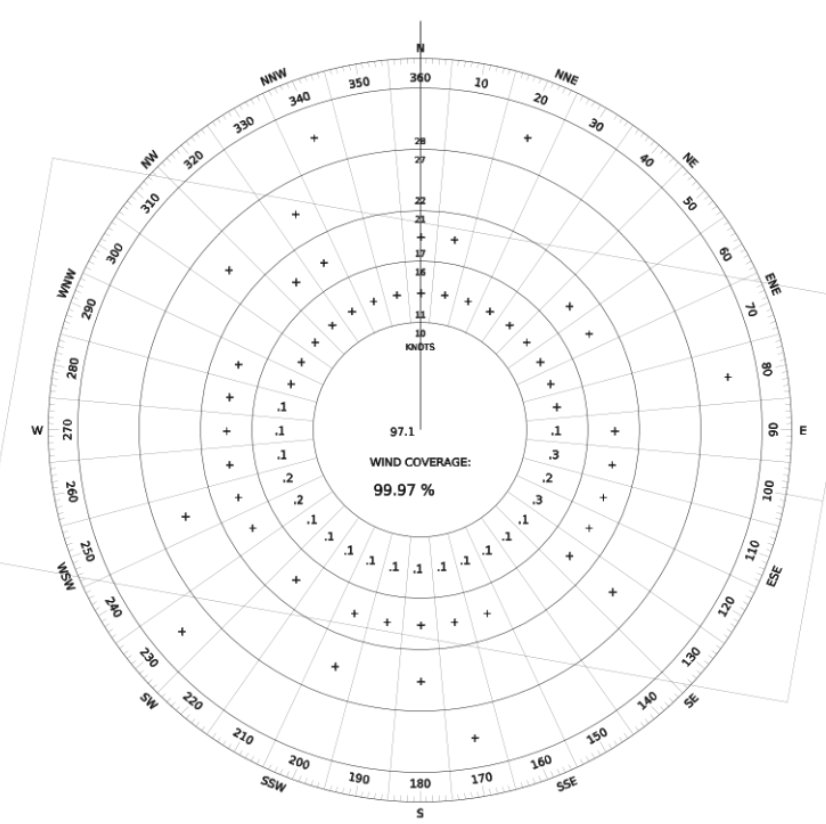

Gambar 2. Mawar Angin Hasil Analisis Airport GIS ALL_WEATHER Wind Rose Form FAA

Tabel 2

Rekapitulasi Pergerakan Pesawat Kedatangan Bandara Syamsudin Noor Tahun $2011-2014$

Kedatangan

\begin{tabular}{llllll} 
& \multicolumn{4}{c}{ Tahun } & \multicolumn{1}{c}{ Bulan } \\
Penerbangan & 2011 & 2012 & 2013 & 2014 & Puncak \\
\hline Domestik & 12031 & 14696 & 15009 & 14924 & Nov \\
Internasional & 32 & 30 & 26 & 46 & Sep \\
\hline \hline
\end{tabular}

Tabel 3

Rekapitulasi Pergerakan Pesawat Keberangkatan Bandara Syamsudin Noor Tahun $2011-2014$

Keberangkatan

\begin{tabular}{llllll} 
& \multicolumn{4}{c}{ Tahun } & \multicolumn{1}{c}{ Bulan } \\
Penerbangan & 2011 & 2012 & 2013 & 2014 & Puncak \\
\hline Domestik & 12042 & 14715 & 15027 & 14401 & Nov \\
Internasional & 35 & 29 & 19 & 50 & Sep \\
\hline \hline
\end{tabular}

Sedangkan digunakan fungsi regresi linear berdasarkan faktor ekonometrik untuk kedatangan dan keberangkatan internasional. Fungsi-fungsi tersebut ada yang didapatkan dengan menambahkan trendline pada grafik pergerakan pesawat bandara Syamsudin Noor pada tahun 2011 - 2015, ada pula yang melalui proses pencarian garis regresi dengan menambahkan faktor data sekunder ekonometrik. Fungsi regresi itulah yang akan digunakan sebagai fungsi peramalan pergerakan pesawat. Regresi bersama dengan analisis pergerakan jam puncak akan dilakukan setelah diketahui kapasitas eksisting runway, agar diketahui kapan pergerakan pesawat melebihi kapasitas runway bandara dan dibutuhkan runway kedua. 
Tabel 4

Fungsi Regresi Untuk Peramalan Pergerakan Pesawat

\begin{tabular}{ll}
\hline \hline $\begin{array}{l}\text { Data } \\
\text { Pergerakan }\end{array}$ & Model Peramalan \\
Pesawat & \\
\hline $\begin{array}{l}\text { Internasional } \\
\text { (Kedatangan) }\end{array}$ & $\mathrm{y}=375 \mathrm{X}_{2}-0.207 \mathrm{X}_{1}-747351.6$ \\
$\begin{array}{l}\text { Internasional } \\
\text { Keberangkata }\end{array}$ & $\mathrm{y}=3.5 \mathrm{x}+24.5$ \\
$\mathrm{n})$ & \\
$\begin{array}{l}\text { Domestik } \\
\text { (Kedatangan) }\end{array}$ & $\mathrm{y}=899,2 \mathrm{x}+11917$ \\
$\begin{array}{l}\text { Domestik } \\
\text { (Keberangkata }\end{array}$ & $\mathrm{y}=898.2 \mathrm{x}+11934$ \\
$\mathrm{n})$ & \\
\hline \hline
\end{tabular}

\section{Analisis Kapasitas Runway Eksisting}

Perhitungan kapasitas runway eksisting dilakukan pada bulan tersibuk, saat dimana jumlah penerbangan melebihi bulanbulan lainnya dalam periode pengamatan. Dari data pergerakan pesawat diketahui bahwa bulan puncak terjadi pada bulan November 2013, dengan total penerbangan Internasional dan Domestik sebanyak 2871 penerbangan. Hari tersibuk pada bulan tersebut adalah pada tanggal 2 November 2013 dengan 99 penerbangan terjadi. Tabel 4.12 merinci pergerakan pesawat di bandara pada 2 November 2013.

\section{1) Kedatangan Saja}

Pada langkah ini akan dihitung kapasitas runway dengan asumsi bahwa runway hanya melayani pesawat yang datang.

\section{2) Keadaan Bebas Kesalahan $\left[M_{i j}\right]$}

Diketahui dari rekomendasi FAA bahwa pemisahan minimum yang dibutuhkan antara dua pesawat secara lateral adalah tergantung dari pengelompokkan berat dan mesinnya [6]. Bila kedua pesawat berada pada kategori I maka pemisahan minimum adalah 3 mil, namun bila salah satu atau keduanya berada pada kategori III maka pemisahan minimum adalah 6 mil.

$$
\mathrm{C}=\frac{3600}{\Delta T}=\frac{3600}{220,66}=16,32 \mathrm{kedatangan} / \mathrm{jam}
$$

\section{3) Keadaan Kesalahan Posisi}

Asumsi terdapat kesalahan posisi $\left(\sigma_{0}\right)$ pada jadwal penerbangan sebesar 20 detik dengan distribusi normal dan probabilitas pelanggaran aturan pisah minimum untuk jarak kedatangan sebesar 10 persen, maka kapasitas runway untuk keadaan kesalahan posisi dapat dihitung.

$$
\mathrm{C}=\frac{3600}{\Delta T}=\frac{3600}{285,39}=12,57 \mathrm{kedatangan} / \mathrm{jam}
$$

\section{4) Keberangkatan Saja}

Pada langkah ini akan dihitung kapasitas runway dengan asumsi bahwa runway hanya melayani pesawat yang berangkat. Metode dalam bagian ini tidak berbeda dengan bagian kedatangan. Tujuan perhitungan adalah mencari kapasitas runway eksisiting $\mathrm{C}$, dengan mencari matriks waktu antar kebarangkatan [tij] dan probabilitas pesawat $\mathrm{i}$ diikuti pesawat $\mathrm{j}$ [pij] yang dikalikan untuk mendapat waktu pemisahan rata-rata
$\Delta T$. Perbedaan mencolok dari bagian sebelumnya adalah bahwa pada saat keberangkatan pemisahan sudah diatur oleh menara control (ATC), begitupun akan diasumsikan bahwa waktu antarkeberangkatan belum diketahui dan [tij] didapatkan dari selisih waktu keberangkatan pesawat $\mathrm{i}$ dan $\mathrm{j}$

$$
\mathrm{C}=\frac{3600}{\Delta T}=\frac{3600}{362,5}=9,93 \text { keberangkatan } / \mathrm{jam}
$$

\section{5) Operasi Campuran}

Langkah selanjutnya dalam menentukan kapasitas runway yaitu menemukan kemungkinan dilakukannya operasi keberangkatan diantara dua kedatangan. Pergerakan pesawat di runway harus mengutamakan pesawat yang akan mendarat (arrivals) karena apabila tundaan (delay) mencapai 30 menit, maka pesawat itu akan dialihkan ke bandara terdekat. Waktu pemakaian runway rata-rata, merupakan jumlah perkalian dari prosentase kategori pesawat dengan waktu pemakaian runway tiap kategori pesawat. Perhitungan dimulai dengan menghitung pemisahan pada keadaan kedatangan saja dan keberangkatan saja. Setelah itu dihitung kapasitas operasi campuran. Dapat dilihat dibawah bahwa sebagian perhitungan telah diselesaikan pada bagian sebelumnya, sehingga untuk operasi campuran ini yang perlu dilakukan adalah mencari waktu antar kedatangan sehingga dapat pada operasi kedatangan tersebut dapat diselingi dengan operasi keberangkatan. Pengecualian untuk pernyataan tersebut adalah perhitungan untuk Runway Occupancy Time yang perlu dihitung secara individu untuk masing-masing tipe pesawat.

$$
C_{m}=\frac{1}{116,039}(1+0,375)=42,658 \text { operasi } / j a m
$$

\section{D.Analisis Peramalan Pergerakan Pesawat Saat Jam Puncak}

Pergerakan pesawat saat jam puncak dapat diramalkan menggunakan fungsi model regresi yang telah dihitung di subbab 4.2.1. Model regresi tersebut menghitung total pergerakan satu rute pergerakan dalam satu tahun, sementara kapasitas runway eksisting yang dihitung di subbab sebelum ini adalah dalam jumlah pergerakan per jam. Agar dapat dibandingkan, keduanya harus berada pada satuan yang sama, yaitu pergerakan pesawat per jam. Perlu diperhatikan bahwa perhitungan kapasitas runway dilakukan pada jam tersibuk pada hari tersibuk dan bulan tersibuk pada tahun 2013, yaitu tahun tersibuk dari data observasi.

Tabel 5

Jenis Rasio dan Rasionya

\begin{tabular}{lc}
\hline \hline Jenis Rasio & Rasio \\
\hline Rasio Bulan Puncak & 0,098 \\
Rasio Hari Puncak & 0,172 \\
Rasi Jam Puncak & 0,03
\end{tabular}

Rasio memudahkan perhitungan peramalan untuk tahun mendatang. Setelah diketahui rasio tersebut, peramalan pergerakan pesawat total dapat dilakukan. 
Tabel 6

Hasil Perhitungan Jumlah Penerbangan Pada Jam Puncak di Tahun Mendatang

\begin{tabular}{|l|l|r|r|r|r|r|r|r|}
\hline \begin{tabular}{|l|l|} 
Tahun \\
ke-
\end{tabular} & Tahun & \multicolumn{3}{|c|}{ Domestik } & \multicolumn{3}{|c|}{ Internasional } & \multirow{2}{*}{ Total } \\
\hline & & Datang & Berangkat & Total & Datang & Berangkat & Total & \\
\hline 6 & 2016 & 9 & 9 & 18 & 0 & 0 & 0 & 18 \\
\hline 7 & 2017 & 9 & 9 & 18 & 0 & 0 & 0 & 19 \\
\hline 8 & 2018 & 10 & 10 & 19 & 0 & 0 & 0 & 19 \\
\hline 9 & 2019 & 10 & 10 & 20 & 0 & 0 & 0 & 20 \\
\hline 10 & 2020 & 11 & 11 & 21 & 0 & 0 & 0 & 21 \\
\hline 15 & 2025 & 13 & 13 & 26 & 0 & 0 & 0 & 26 \\
\hline 20 & 2030 & 15 & 15 & 30 & 0 & 0 & 0 & 31 \\
\hline 25 & 2035 & 17 & 17 & 35 & 0 & 0 & 0 & 35 \\
\hline 33 & 2043 & 21 & 21 & 42 & 0 & 0 & 1 & 43 \\
\hline 35 & 2045 & 22 & 22 & 44 & 1 & 0 & 1 & 45 \\
\hline
\end{tabular}

\section{Pergerakan Pesawat Total pada Jam Puncak}

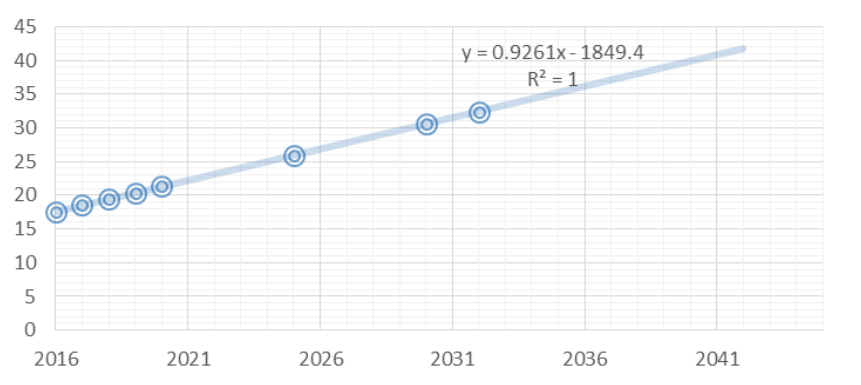

Gambar 3. Grafik Model Regresi Linear Pergerakan Pesawat Total pada Jam Puncak

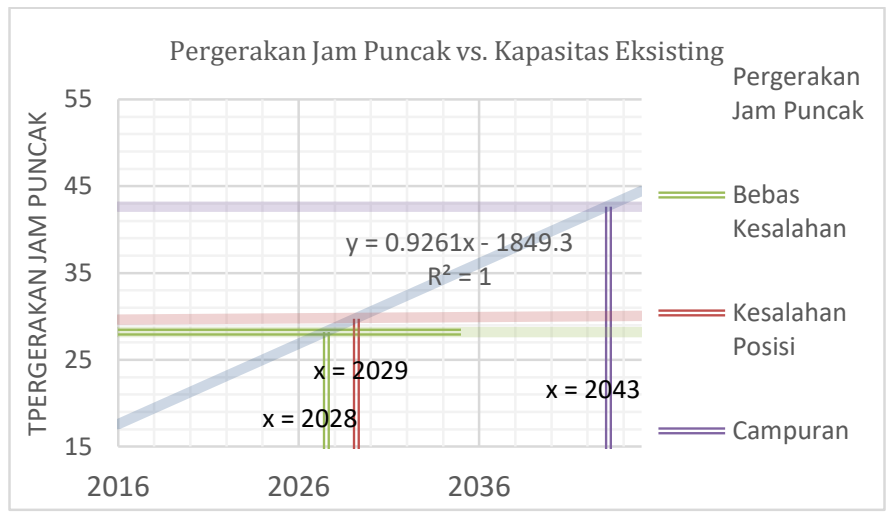

Gambar 4. Pergerakan Pesawat Pada Jam Puncak di Tahun Mendatang dan Kapasitas Eksisting Untuk Berbagai Kondisi

Hasil perhitungan menyimpulkan bahwa runway tunggal Bandar Udara Syamsudin Noor butuh untuk ditambah jumlahnya pada masa mendatang agar dapat melayani pesawat yang dating dan berangkat. Tahun dibutuhkannya runway tambahan adalah pada tahun 2028 pada keadaan bebas kesalahan, tahun 2029 untuk keadaan kesalahan posisi, dan pada tahun 2043 untuk keadaan operasi campuran antara datang dan berangkat. Studi ini mengasumsikan bahwa operasi campuran dengan satu operasi keberangkatan diantara dua operasi kedatangan adalah yang berlaku di masa mendatang, sehingga tahun dibutuhkannya runway tambahan di Bandara Syamsudin Noor adalah pada tahun 2043.

\section{E. Perencanaan Runway, Exit Taxiway dan Taxiway}

Analisis kapasitas runway pada subbab 4.2 menunjukkan bahwa pada tahun 2032 runway eksisting tidak dapat menampung pergerakan pesawat yang muncul. Perencanaan runway tambahan diperlukan untuk meningkatkan kapasitas pergerakan pesawat yang dapat dilayani oleh Bandar Udara Syamsudin Noor Banjarmasin. Subbab ini akan merencanakan runway tambahan beserta taxiway dan exit taxiway-nya. Perencanaan meliputi system, dimensi, dan fasilitas terkait runway, taxiway dan exit taxiway.

ARFL (Aeroplane Reference Field Length) yang didapatkan dari proses sebelum ini dapat dikategorikan menurut ARC (Aerodrome Reference Code), yaitu kode dari ICAO untuk bandara berdasarkan ARFL dan karakteristik pesawat terbesar. Didapakatkan ARC adalah 4C karena bentang sayap pesawat terbesar Boeing 737-900 sebesar 35,8 meter dan nilai ARFL dari bagian sebelumnya yaitu 3326 meter.

Lebar landas pacu, atau runway dapat diketahui dari tabel pada dokumen SKEP 772005 oleh Dirjen Perhubungan [7]. Dalam tabel tersebut dirinci lebar runway menurut ARC yang telah diketahui. Untuk kasus runway rencana bandara Syamsudin Noor ini karena ARC diketahui 4C, dan didapatkan lebar runway sebesar $45 \mathrm{~m}$ dari tabel.

Arti dari pemusahan runway disini adalah jarak antara runway dengan halangan berupa objek atau fasilitas bandara lainnya, contohnya yaitu landasan hubung atau taxiway. Pemisahan ini adalah jarak antara garis tengah (centerline) runway dengan garis tengah (centerline) taxiway. Sementara pemisahan lain adalah pemisahan pesawat yang sedang melakukan holding di taxiway dan garis tengah runway, pemisahan ini disebut holdline. Pemisahan lainnya adalah jarak antara garis tengah runway dan area parkir pesawat. Ketiga pemisahan tersebut didapatkan dari tabel pada dokumen SKEP 77 2005[7]. Mengetahui bahwa pesawat terbesar, yaitu Boeing 737-900 masuk kedalam kelompok approach D III sebab kecepatan approach sebesar 141 knot, tail height sebesar 41,4 feet, dan wingspan sebesar 117,4 feet maka didapatkan holdine sepanjang 75 meter, pemisahan garis tengah taxiway ke runway sebesar $120 \mathrm{~m}$ dan jarak ke area parker pesawat sebesar $150 \mathrm{~m}$.

\section{KESIMPULAN}

Berdasarkan hasil analisis dan pembahasan serta mengacu pada tujuan penelitian, maka dapat disimpulkan :

1) Bandara Syamsudin Noor Banjarmasin mempunyai cakupan angin merata di semua arah dengan besaran 0 sampai lebih dari 41 knot. Frekuensi angin terjadi paling banyak pada kondisi calm $(0-5$ knot $)$ menurut ALL_WEATHER Wind Rose Form FAA. Runway eksisting 10 - 28 Bandara Syamsudin Noor Banjarmasin memenuhi syarat FAA dengan cakupan (coverage) angin sebesar 99,87\% menggunakan Airports GIS FAA. Syarat tersebut membuktikan bahwa runway eksisting Bandara Syamsudin Noor cukup untuk melayani bandara Syamsudin Noor.

2) Pergerakan pesawat di Bandara Syamsudin Noor Banjarmasin mempunyai jumlah sedikit, yaitu 12042 hingga 15027 pesawat per tahun menurut Angkasa Pura 
dengan data dari tahun 2011 hingga 2015. Pesawat yang dilayani oleh bandara bervariasi dari Cessna hingga Boeing dengan jadwal pesawat paling padat 15 pergerakan (landing/take-off) pada jam puncak menurut data pergerakan pesawat.

3) Runway eksisting mempunyai kapasitas operasi campuran dengan satu kedatangan diantara dua keberangkatan sebesar 43 operasi/jam. Runway masih dapat melayani pergerakan pesawat pada jam puncak dengan total 15 operasi/jam.

4) Runway tidak dapat melayani pergerakan pesawat pada tahun 2043 untuk total rute kedatangan dan keberangkatan, internasional dan domestik berdasarkan model regresi yang disintesa dengan data pergerakan pesawat tahun 2011-2015.

5) Runway kedua akan diletakkan di arah 100 hingga 280 derajat azimuth. Arah tersebut sama dengan arah runway eksisting sebab memenuhi cakupan minimum untuk single runway menurut FAA dengan persentase 99,97\% dibawah cakupan angin yang dibolehkan.untuk melayani pergerakan pesawat pada tahun 2043 dan setelahnya.

6) Runway kedua diletakkan pada arah 100 hingga 280 derajat azimuth. Hal ini karena hasil analisis windrose yang menyimpulkan bahwa runway 10-28 memenuhi persyaratan cakupan angin menurut FAA. Sebab itu, dipilihlah arah tersebut untuk runway rencana, dan karena demikian maka sistem runway yang dianut adalah sistem paralel.
7) Untuk menentukan dimensi runway, exit taxiway dan taxiway baru di Bandara Syamsudin Noor Banjarmasin digunakan pedoman standar FAA dan Dirjen Perhubungan Udara Indonesia. Dimensi yang dibutuhkan akan ditentukan menggunakan tipe pesawat yang paling besar berat takeoff dan klasifikasinya dalam pengelompokan runway menurut FAA.

8) Runway kedua dapat melayani pergerakan pesawat pada jam puncak di tahun 2043 berdua dengan runway eksisting berdasarkan perhitungan kapasitas runway dengan pola seperti pada jam puncak. Runway rencana dan eksisting dengan kapasitas total 86 operasi/jam dapat menangani pergerakan pesawat total pada jam puncak sebanyak 45 operasi/jam.

\section{DAFTAR PUSTAKA}

[1] "Bandar Udara Syamsudin Noor," wikipedia, 2017. [Online]. Available:

https://id.wikipedia.org/wiki/Bandar_Udara_Syamsudin_Noor.

[2] H. Ocherudy, "Evaluasi Fasilitas Sisi Udara Bandar Udara Syamsudin Noor Banjarmasin Dalam Memfasilitasi Pertumbuhan Pergerakan Pesawat," ITS, 2016.

[3] F. A. Administration, Advisory Circular 150/5300-13A Airport Design, U.S. Department of Transportation. 2014.

[4] F. A. Administration, "ALL_WEATHER Wind Rose Form," 2017. [Online]. Available: https://airportsgis.faa.gov/agis/publicToolbox/windroseForm.jsp .

[5] F. A. Administration, "Wind Rose Form," 2017. [Online]. Available: https://airports-gis.faa.gov/windRose/.

[6] F. A. Administration, Airport Capacity and Delay. Washington DC: Department of Transportation, 1983.

[7] D. J. Perhubungan, Persyaratan Teknis Pengoperasian Fasilitas Teknik Bandar Udara, Pub. L. No. SKEP 77-VI-2005. 2005. 